\title{
HOW CAN PSYCHOLOGISTS AND PSYCHIATRISTS HELP COVID-19 BEREAVED PERSONS: FIVE PROPOSITIONS TO UNDERSTANDING CONTEXTUAL CHALLENGES
}

\begin{tabular}{c} 
Cyrille Kossigan Kokou-Kpolou, PhD ${ }^{1 *}$, Jude Mary Cénat, PhD ${ }^{2}$, \\
María Nieves Pérez-Marfil,PhD, Prof. ${ }^{3}$, Manuel Fernández-Alcántara, PhD \\
\hline${ }^{1}$ Department of Psychology, University of Picardy Jules Verne, France. E-mail: kkkcyrille@yahoo.fr \\
${ }^{2}$ School of Psychology, University of Ottawa, Ontario, Canada. E-mail: jcenat@uottawa.ca \\
${ }^{3}$ Mind, Brain and Behavior Research Center (CIMCYC-UGR), University of Granada, Granada, \\
Spain. E-mail: nperez@ugr.es \\
${ }^{4}$ Department of Health Psychology, University of Alicante, Spain. E-mail: mfernandeza@ua.es \\
\hline \hline
\end{tabular}

\begin{abstract}
The COVID-19 pandemic is causing unprecedented cumulative deaths and leaving behind millions of bereaved families and individuals. Moreover, the pandemic is disrupting social fabrics in the conventional way we mourn our deads. In this context therefore, how can psychologists, psychiatrists and other health care professionals help bereaved families and individuals more effectively? This opinion paper proposed five recommendations that cover mental health care needs and challenges which may emerge from the management of these traumatic deaths. In all, efforts to comply with either DSM5 or ICD-11 PGD guidelines could help COVID-19 bereaved persons with overwhelming distress, as they ensure therapists' use of appropriate terminologies in therapeutic alliances. However, clinicians need to have a global perspective of COVID-19 bereavement courses, political and public health measures due to the pandemic, and flexible attitudes about the ICD-11 and of DSM-5 time-criterion for diagnosis. This paper emphasizes the importance of social and collective recognition of COVID-19 deaths through various symbolic and materialized forms to free up collective and individual capacities for resilience. The necessity of individual and group interventions through online platforms is underscored, however these modes of therapies may not reinforce social inequalities by excluding bereaved individuals who really need them.
\end{abstract}

Keywords: Covid-19 deaths; Prolonged grief disorders; assessment; therapies

\footnotetext{
* Correspondence concerning this article should be addressed to Cyrille Kossigan Kokou-Kpolou, University of Picardy Jules Verne - Department of Psychology, 1 Chemin du Thil CS52501, 80025 Amiens Cedex 1.

E-mail:kkkcyrille@yahoo.fr
} 


\section{Introduction}

The current coronavirus disease 2019 (COVID-19) pandemic has caused and is still causing a considerable number of deaths, currently estimated at over 1 million with over 50 million reported cases worldwide (World Health Organization [WHO], 2020). In United States, according to the pessimistic prognostic scenario made by Verdery and Smith-Greenaway (2020), 1.238 million White and Black Americans will lose a parent and 2.381 million at least one grandparent due to the epidemic. These unprecedented cumulative deaths are leaving behind millions of bereaved families and individuals. In addition, the pandemic is disrupting social fabrics in the conventional way we mourn our deaths. The circumstances of COVID19 deaths embed several traumatic characteristics which predict a probable exponential rise in prolonged grief disorder (PGD) and related health and stress disorders, including posttraumatic disorders, anxiety and depression (Eisma, Boelen \& Lenferink, 2020; Kokou-Kpolou, Fernández-Alcántara, \& Cénat, 2020a) as well severe forms of guilt and somatization (Kokou-Kpolou et al., 2020a). Previous metaanalytic research has consistently shown that 3 to 5 out of 10 persons develop PGD following death in traumatic circumstances of loved ones (Djelantik et al., 2020; Kokou-Kpolou et al., 2020b). However, the literature lacks of reliable information about grief disorders specifically related to previous epidemic or pandemic situations. Therefore, in the context of the present COVID-19 pandemic situation, how can psychologists, psychiatrists and other health care professionals help bereaved families and individuals more effectively? We address this timely question through five context-related propositions that cover the mental health care needs and challenges which may emerge from the management of these traumatic deaths.

We begin with a brief historical note. In fact, psychologists and psychiatrists have always played, often discreet, but prominent roles in mental health care for bereaved persons in times of wars and natural disasters. For instance, Sigmund Freud's pioneering reflections on mourning process were developed during World War I and were pursued by Lindemann in 1943-44 with bereaved victims of the Cocoanut fire in Boston, US (Lindemann, 1944). However, these works and subsequent others classified grief symptoms into those of depression, PTSD, anxiety, and adjustment disorders, sometimes resulting in a mix-up of these pathological conditions. More contemporaneous advances in both research and treatment efforts have demonstrated that pathological grief forms a bereavement specific syndrome (PGD), distinct from other psychopathologies (Boelen and van den Bout, 2005; Boelen, van de Schoot, van den Hout, de Keijser, \& van den Bout, 2010; Horowitz et al., 1997; Prigerson et al., 2009). 


\section{Compliance with PGD Guidelines}

What psychologists, psychiatrists and other health care workers should be reminded of is that all griefs do not develop in normal ways. The two international leading systems for the classification of disorders (International Classification of Mental Diseases- $11^{\text {th }}$ edition [ICD-11] and Diagnostic and Statistical Manual of Mental Disorders- $5^{\text {th }}$ edition [DSM-5]) recently incorporated PGD as a condition that requires formal diagnoses and therapeutic interventions (WHO, 2018; American Psychiatric Association, 2020). Efforts had been made as of June 2019 to harmonize the PGD criteria of both classification systems, even though discrepancies still exist on time-criterion for PGD diagnosis and on the number of symptoms associated to PGD (Boelen, Eisma, Smid, \& Lenferink, 2020; Lenferink, Boelen, Smid, \& Paap, 2019). Although there have been some reservations from some clinicians in diagnosing pathological grief as a disorder, psychometric studies confirmed that PGD tests presented excellent diagnostic sensitivity and specificity to identify "true" PGD cases (Boelen, Djelantik, de Keijser, Lenferink, \& Smid, 2019; Cozza et al., 2020; Maciejewski, Maercker, Boelen, \& Prigerson, 2016). Aslo, evidence from longitudinal follow-up studies has shown that using PGD guidelines in earlier assessment of grief reactions can help to predict future complications in the bereavement course and health outcomes (Sveen, Johannesson, Cernvall, \& Arnberg, 2018; Tsai, Kuo, Wen, Prigerson, \& Tang, 2018). Efforts to comply with PGD guidelines could help COVID-19 bereaved persons with overwhelming distress, as they ensure therapists' use of appropriate terminologies in therapeutic alliances and to provide care tailored to identified high-risk groups (Tsai et al., 2018).

\section{Time-Criterion for PGD Diagnosis in the COVID-19 Context}

From a clinical perspective, it is usually expected that the severity of grief symptoms recedes over time after the bereavement, with a time-criterion of 6 months according to the ICD-11 and of 12 months according to the DSM-5. However, it is expected that COVID-19 death experiences may challenge this time-criterion (Kokou-Kpolou et al., 2020a). In fact, rather than the date of the death, the date of the burial and funeral anchors the "starting" point in the grieving process because it marks the moment of social recognition of the irreversible reality of loss. In the COVID-19 pandemic context, funerals in many cases are postponed, perhaps for an indefinite period. This context, imposed by the pandemic, requires attention from health care providers to guide families and individuals who can develop a delayed form of mourning. Therefore, it is important to consider the distinct long-term trajectories following the death of a loved one including resilience, recovery, delayed and chronic dysfunction (Galatzer-Levy, Huang, \& Bonanno, 2018). 


\section{Health and Political Decisions Will Influence COVID-19 Bereavement Courses}

In addition to the above points, clinicians need to have a global perspective of COVID-19 bereavement courses for families and individuals. In most affected countries, families have been forbidden from approaching their sick or dying relatives in intensive care units. Within a short period of time, it became almost impossible for families to see nor speak with their sick relatives again, to note his/her death, nor to even invite close relations to funeral ceremonies which are forbidden or postponed for up to six months after the death (Kokou-Kpolou et al., 2020a; Lazzerini and Putoto, 2020). In France, Italy and Spain, for example, there were immediate protests requesting changes to these prohibitions. While the storm of the pandemic will be behind, families will think about the specific circumstances surrounding the death of their loved ones in moving on with their mourning process. Thus, political and public health measures imposed due to the pandemic will be questioned and the shortcomings will lead to feelings of anger or rage and guilt about the way COVID-19 deaths were managed. These feelings could worsen the healthy mourning process and outcomes. Therefore, taking these contextual elements into account, not only episodic but also systemic perspective, is necessary to avoid an overpathologization of the response to COVID-19 death and an individualization of mourning emotions.

\section{Social and Collective Acknowledgement of COVID-19 Deaths}

In situations of mass deaths, such as the COVID-19 situation, therapeutic effectiveness for mourning and trauma in individuals may be blocked when there is no social, collective and symbolic recognition of deaths, or when such recognition takes a long time to be put in place. This recognition can be materialized in various forms, depending on policy makers, to free up collective and individual capacities for resilience in response to COVID-19 deaths (Kokou-Kpolou et al., 2020a). At the scale of localities, cities and districts harshly affected by the COVID-19 pandemic, and at the nationwide scale, meaning-making practices should be organized to accompany our dead (Kokou-Kpolou et al., 2020a), including, but not limited to, collective funerals, community-based virtual funerals, and creation of stellas. The context of the pandemic may be perceived as a traumatic event that undermines our inner system of core beliefs, which may negatively impact in mental health on an individual and social level (Milman, Lee, \& Neimeyer, 2020). These death rituals and symbolisms help in enhancing self-control, in meaning-making and in the regulation of complex emotions and avoidant or intrusion thoughts surrounding death (Payàs Puigarnau and Chaurand Morales, 2019). 
At the community and family level, family cohesion fostering adequate emotional and material support, compassionate communication about the dying and the death of the loved person may strength resilience and adjustment to the loss (Chen and Bonanno, 2020). It falls under the responsibility of local institutions to promote adequate quantity of information about and access to health care and recreational activities, mainly for bereaved individuals with precarious socioeconomic status (Chen and Bonanno, 2020). These measures are likely to alleviate social anger over the deficiencies in management of COVID deaths and to foster national solidarity in individual mourning.

\section{Forms of Grief Interventions in Times of COVID-19 pandemic}

With the COVID-19 pandemic, e-health services are blowing up all over the world (Liu et al., 2020). Before the pandemic, there has been a surge in online-based grief therapies over the past few years (Robinson and Pond, 2019). Both individual and group interventions through online platforms seem to foster peer support, reconstruction of identity and normalization of the grief process. Moreover, these interventions should consider the traumatic aspect of death, the feelings of isolation in the first moments of grief, as well as the limitations of social support during the pandemic.

These new modes of therapy will increase given the social distancing policies. However, there is a concern that they may reinforce social inequalities by excluding those who really need them (Cénat et al., 2020). Cumulative evidence has shown that bereaved people who live in precarious social and financial conditions are more concerned by severe grief reactions and related consequences. The unprecedent economic and financial crisis the pandemic has caused, marked by abrupt loss of resources by families, may lead to them disregarding their health care needs. In such contexts, facilitating access to grief services and interventions for those who are in greater need would be important in helping families and individuals bereaved by COVID-19 deaths.

In conclusion, health care workers should consider the complex and multifaceted presentation of grief, giving special attention to the traumatic symptoms and being flexible regarding the time criteria in the COVID-19 context. Political and social interventions are also needed to guarantee the attention and support to people whose financial or social conditions have been disrupted by the pandemic. Finally, novel approaches, including online therapy are needed to support these unexpected losses and griefs. And importantly, given that health care professionals are more at risk for developing severe mental health problems (including anxiety, depression, burnout, stress and post-traumatic stress disorders symptoms) than general public (Luo, Guo, Yu, \& Wang, 2020) they have to help, it is necessary that government 
and main authorities design specific actions to protect their mental health and wellbeing and to promote their resilience abilities during and post COVID-19 context.

\section{References}

American Psychiatric Association. (2020). View and comment on recently proposed changes to DSM-5. Retrieved from https://www.psychiatry.org/psychiatrists/ practice/dsm/proposed-changes

Boelen, P. A., Eisma, M. C., Smid, G. E., \& Lenferink, L. I. M. (2020). Prolonged grief disorder in section II of DSM-5: a commentary. European Journal of Psychotraumatology, 11, 1. https://doi.org/10.1080/20008198.2020.1771008

Boelen, P. A., Djelantik, A. A. A. M. J., de Keijser, J., Lenferink, L. I. M., \& Smid, G. E. (2019). Further validation of the Traumatic Grief Inventory-Self Report (TGI-SR): A measure of persistent complex bereavement disorder and prolonged grief disorder. Death Studies, 43(6), 351-364. https://doi.org/ 10.1080/07481187.2018.1480546

Boelen, P. A., van de Schoot, R., van den Hout, M. A., de Keijser, J., \& van den Bout, J. (2010). Prolonged Grief Disorder, depression, and posttraumatic stress disorder are distinguishable syndromes. Journal of Affective Disorders, 125(13), 374-378. https://doi.org/10.1016/j.jad.2010.01.076

Boelen, P. A., \& van den Bout, J. (2005). Complicated Grief, Depression, and Anxiety as Distinct Postloss Syndromes: A Confirmatory Factor Analysis Study. American Journal of Psychiatry, 162(11), 2175-2177. https://doi.org/ 10.1176/appi.ajp.162.11.2175

Cénat, J. M., Dalexis, R. D., Kokou-Kpolou, K. C., Mukunzi, J., \& Rousseau, C. (2020). Social inequalities and collateral damages of the COVID-19 pandemic: when basic needs challenge mental health care. International Journal of Public Health, https://doi.org/10.1007/s00038-020-01426-y

Chen, S., \& Bonanno, G. A. (2020). Psychological adjustment during the global outbreak of COVID-19: A resilience perspective. Psychological Trauma: Theory, Research, Practice, and Policy. https://doi.org/10.1037/tra0000685

Cozza, S. J., Shear, M. K., Reynolds, C. F., Fisher, J. E., Zhou, J., Maercker, A., ... Ursano, R. J. (2020). Optimizing the clinical utility of four proposed criteria for a persistent and impairing grief disorder by emphasizing core, rather than associated symptoms. Psychological Medicine, 50(3), 438-445. https://doi.org/ 10.1017/S0033291719000254

Djelantik, A. A. A. M. J., Smid, G. E., Mroz, A., Kleber, R. J., \& Boelen, P. A. (2020). The prevalence of prolonged grief disorder in bereaved individuals following unnatural losses: Systematic review and meta regression analysis. Journal of Affective Disorders, 265, 146-156. https://doi.org/10.1016/j.jad. 2020. 01.034 
Eisma, M. C., Boelen, P. A., \& Lenferink, L. I. M. (2020). Prolonged grief disorder following the Coronavirus (COVID-19) pandemic. Psychiatry Research, 288, 113031. https://doi.org/10.1016/j.psychres.2020.113031

Galatzer-Levy, I. R., Huang, S. H., \& Bonanno, G. A. (2018). Trajectories of resilience and dysfunction following potential trauma: A review and statistical evaluation. Clinical Psychology Review, 63, 41-55. https://doi.org/10.1016/ j.cpr.2018.05.008

Horowitz, M. J., Siegel, B., Holen, A., Bonanno, G. A., Milbrath, C., \& Stinson, C. H. (1997). Diagnostic criteria for complicated grief disorder. American Journal of Psychiatry, 154(7), 904-910. https://doi.org/10.1176/ajp.154.7.904

Kokou-Kpolou, C. K., Fernández-Alcántara, M., \& Cénat, J. M. (2020). Prolonged grief related to COVID-19 deaths: Do we have to fear a steep rise in traumatic and disenfranchised griefs? Psychological Trauma: Theory, Research, Practice, and Policy. https://doi.org/10.1037/tra0000798

Kokou-Kpolou K. Moukouta C.S., Masson J., Bernoussi A., Cénat J. M., B. M.-F. (2020). Correlates of Grief-Related Disorders and Mental Health Outcomes among Adult Refugees Exposed to Trauma and Bereavement: A Systematic Review and Future Research Directions. Journal of Affective Disorders, 276, 171-184. https://doi.org/doi:10.1016/j.jad.2020.02.026

Lazzerini, M., \& Putoto, G. (2020). COVID-19 in Italy: Momentous decisions and many uncertainties. Lancet Global Health, 8, e641-e642. http://dx.doi.org/10. 1016/S2214-109X(20)30110-8

Lenferink, L. I. M., Boelen, P. A., Smid, G. E., \& S Paap, M. C. (2019). The importance of harmonising diagnostic criteria sets for pathological grief. The British Journal of Psychiatry. https://doi.org/10.1192/bjp.2019.240

Lindemann, E. (1944). Symptomatology and management of acute grief. American Journal of Psychiatry, 101(2), 141-148. https://doi.org/10.1176/ajp.101.2.141

Milman, E., Lee, S. A., \& Neimeyer, R. A. (2020). Social isolation and the mitigation of coronavirus anxiety: The mediating role of meaning. Death Studies, 1-13. https://doi.org/10.1080/07481187.2020.1775362

Maciejewski, P. K., Maercker, A., Boelen, P. A., \& Prigerson, H. G. (2016). "Prolonged grief disorder" and "persistent complex bereavement disorder", but not "complicated grief", are one and the same diagnostic entity: an analysis of data from the Yale Bereavement Study. World Psychiatry, 15(3), 266-275. https://doi.org/10.1002/wps.20348

Luo, M., Guo, L., Yu, M., \& Wang, H. (2020). The Psychological and Mental Impact of Coronavirus Disease 2019 (COVID-19) on Medical Staff and General Public - A Systematic Review and Meta-analysis. Psychiatry Research 291, 113190.

Payàs Puigarnau, A., \& Chaurand Morales, A. (2019). Unfolding Meaning From Memories: An Integrative Meaning Reconstruction Method for Counseling the Bereaved. Illness, Crisis \& Loss, 27(3), 209-225. https://oi.org/10.1177/ 1054137316687954 
Prigerson, H. G., Horowitz, M. J., Jacobs, S. C., Parkes, C. M., Aslan, M., Goodkin, K., ... Maciejewski, P. K. (2009). Prolonged Grief Disorder: Psychometric Validation of Criteria Proposed for DSM-V and ICD-11. PLoS Medicine, 6(8), e1000121. https://doi.org/10.1371/journal.pmed.1000121

Robinson, C., \& Pond, D. R. (2019). Do online support groups for grief benefit the bereaved? Systematic review of the quantitative and qualitative literature. Computers in Human Behavior, 100, 48-59. https://doi.org/10.1016/j.chb. 2019.06.011

Sveen, J., Bergh Johannesson, K., Cernvall, M., \& Arnberg, F. K. (2018). Trajectories of prolonged grief one to six years after a natural disaster. PLOS ONE, 13(12), e0209757. https://doi.org/10.1371/journal.pone.0209757

Tsai, W.-I., Kuo, S.-C., Wen, F.-H., Prigerson, H. G., \& Tang, S. T. (2018). Prolonged grief disorder and depression are distinct for caregivers across their first bereavement year. Psycho-Oncology, 27(3), 1027-1034. https://doi.org/ 10.1002/pon.4629

Verdery, A. M., \& Smith-Greenaway, E. (2020). COVID-19 and family bereavement in the United States. Applied Demography, 32(1), 1-20. Retrieved from http://www.populationassociation.org/wp-content/ uploads/CAD_SpecialEdition_COVID19_March2020.pdf\#page3

World Health Organization, WHO. (2020). Coronavirus COVID-19 Global Cases by the Center for Systems Science and Engineering (CSSE) at Johns Hopkins University (JHU). https://coronavirus.jhu.edu/map.html. Accessed on 18 July 2020 . 